\title{
Mobilidade precária em Terra estrangeira e em Estive em Lisboa e lembrei de você
}

\author{
Marco Antonio Rodrigues ${ }^{1}$
}

Foi a Portugal, perdeu o lugar

Foi ao vento, perdeu o assento

(dito popular)

São Paulo, capital, arredores do Minhocão, início da década de 1990. O jovem Francisco Eizaguirre (Paco), estudante universitário e aspirante a ator, parte sozinho para Portugal, levando uma suspeita encomenda, mas com o nobre propósito de visitar na Espanha a terra natal de sua mãe, recém-falecida.

Cataguases, Minas Gerais, início dos anos 2000. O já não tão jovem Sérgio Sampaio (Serginho), desempregado, separado (a esposa no manicômio), um filho ainda novo tomado pela família da esposa, segue também rumo a Portugal, em busca de trabalho, prosperidade econômica e reconhecimento na terra de origem.

Trata-se de personagens da arte narrativa brasileira contemporânea. Paco é o protagonista de um dos mais bem-sucedidos filmes nacionais da década de 1990, Terra estrangeira, longa-metragem de 1995 dirigido por Walter Salles e Daniela Thomas. Serginho é o narrador-protagonista da novela Estive em Lisboa e lembrei de você, do ficcionista Luiz Rufatto, lançada em 2009, pela coleção Amores Expressos. Em comum, além do destino de viagem de seus protagonistas, as obras compartilham a representação de situações de mobilidade geográfica que beiram a ilegalidade, e que se realizam em contextos de privação material.

Se, em Terra estrangeira, o problema central proposto pelos realizadores é retratar "um novo exílio, econômico, que estaria transformando o Brasil dos anos noventa num país de emigração" (Thomas; Bernstein; Salles, 1996, p. 5), em Estive em Lisboa é é já a rotinização dessa rota de emigração moderna: a classe média baixa vai ao paraíso via Portugal, porta de entrada de brasileiros e outros povos colonizados para a União Europeia. A expectativa com melhores condições de trabalho, a língua comum e as afinidades culturais são atrativos que levam os aventureiros a inverter o

\footnotetext{
${ }^{1}$ Doutorando em Literatura pela Universidade de Brasília (UnB), Brasília, Brasil. Mestre em Literatura Brasileira pela Universidade de São Paulo (USP). E-mail: marco_arod@yahoo.com.br

${ }^{2}$ A fim de não comprometer a fluência do texto, doravante será adotada essa forma abreviada de referência ao texto de Luiz Rufatto.
} 
velho "sentido da colonização", transformando o ocupado em ocupante e como que requisitando junto ao ocupante original o restabelecimento de sua dependência, desta vez sob um regime mais digno, de subemprego.

A escolha desse objeto de representação pelo cinema e pela literatura sugere a importância do fato social e seus desdobramentos nos locais de origem e de destino. Se em Terra estrangeira o que parece estar em discussão é uma espécie de desistência da identidade brasileira, ou mesmo da identidade em geral, em Estive em Lisboa estamos diante de uma figura semelhante a milhares de brasileiros que emigraram para Portugal valendose da isenção do visto de turismo prevista pela legislação. A opção por um substrato social desprestigiado é significativa, ao retratar uma mobilidade voluntária que ocorre bem distante da mobilidade das elites, mas que também se distancia das grandes vítimas da globalização - aqueles que, presos a sua territorialidade, sentem-se incapazes de domesticar e se apropriar da localidade da qual têm pouca chance de se libertar (Bauman, 1999, p. 25).

Na ausência de termo mais apropriado, utilizaremos a expressão "mobilidade precária" para designar esse fenômeno que se desenvolve na fronteira da ilegalidade e da total privação de recursos, sugerindo que a mobilidade pode ser facilitada pelo alto poder aquisitivo, mas não está circunscrita a essa condição. Interessa particularmente a este artigo não o fenômeno em si, mas a sua representação nas obras ficcionais já mencionadas. Nelas encontraremos as sugestões de que a mobilidade espacial não significa mobilidade social, e que uma mobilidade precária resulta em identidade igualmente precária.

\section{Mobilidade e identidade}

Por mais lembrada e citada que seja pelas diferentes frentes de nossa cultura, a famosa síntese de Paulo Emílio sobre quem somos, os brasileiros, continua a nos intrigar e a nos surpreender. Ela aparece, pela primeira vez, no primeiro número da revista Argumento, em um contexto de repressão política da ditadura militar, em 1973. Tratando de cinema e subdesenvolvimento, Paulo Emílio faz uma distinção entre o nosso e outros povos colonizados, para os quais seria mais producente a distinção entre "ocupante" e "ocupado", enquanto, para o Brasil, o segundo teria sido criado à imagem e semelhança do primeiro. Citando a passagem da síntese propriamente dita: "Não somos europeus nem americanos do norte, mas destituídos de cultura original, nada nos é estrangeiro, pois tudo o é. A penosa construção de nós mesmos se desenvolve na dialética rarefeita entre o não ser e o ser outro" (Salles Gomes, 1973, p. 58). 
A engenhosidade da formulação reside principalmente na consciência sobre o caráter negociado, construído, dessa identidade, bem como sobre a precariedade dessa construção, esboçada não a partir do que de fato a constitui, mas daquilo que a contradiz, o "não ser e o ser outro". Algo que a sociologia mais recente tem definido como uma "crise de identidade" (Hall, 2006, p. 7), não de um grupo ou de uma nacionalidade específica, mas da própria pós-modernidade, associada ao abandono da noção de sujeito unificado e ao enfraquecimento da ideia de nacionalidade, com o advento da globalização. É curiosa a sintonia existente, inclusive no elemento constituinte de ambas as conceituações, posto que, para Stuart Hall, é apenas por meio da relação com o outro, com "aquilo que falta", que o sentido positivo da identidade pode ser construído (Hall, 2000, p. 110).

Isso tudo, porém, era muito embrionário para o contexto de Paulo Emílio, num momento em que a visão do intelectual brasileiro ainda pagava tributos à ideia de um "caráter nacional", tão cara aos intelectuais de décadas anteriores. Não por acaso, os termos de comparação de Paulo Emílio são europeus e norte-americanos, e o princípio de indistinção entre ocupante e ocupado pressupõe uma bem-sucedida política de branqueamento, mediante a "importação maciça de reprodutores seguida de cruzamento variado", assegurando o êxito na criação de um novo ocupado (Salles Gomes, 1973, p. 57).

Já na década de 1990, porém, o fenômeno da globalização e seus teóricos irão reposicionar a discussão identitária, tratando-a principalmente como descentrada do sujeito e libertada do estático. Para Zygmunt Bauman, a ideia de "ter uma identidade" não vai ocorrer às pessoas enquanto o "pertencimento" continuar sendo o seu destino, uma condição sem alternativa (Bauman, 2005, p. 18), pois é fora da comunidade de origem que esse questionamento irá se impor de forma mais urgente e necessária. Stuart Hall expõe questão semelhante, destacando que as identidades são construídas por meio da diferença, e não fora dela (Hall, 2000, p. 110). Identidade e mobilidade seriam, portanto, questões irmãs. Bauman, aliás, associa ambas as aspirações ao poder econômico, o que limitaria seu pleno usufruto a uma elite, capaz de deslocar-se ao sabor de sua vontade e de reivindicar as identidades que lhe parecerem convenientes:

Com as distâncias não significando mais nada, as localidades, separadas por distâncias, também perdem seu significado. Isso, no entanto, augura para alguns a liberdade face à criação de significado, mas para outros pressagia a falta de significado. Alguns podem até mover-se para fora da localidade - qualquer localidade - quando quiserem. Outros observam, impotentes, a única localidade que habitam movendo-se sob seus pés. (Bauman, 1999, p. 25) 
De forma similar, a identidade seria, para Bauman, plenamente acessível a um grupo restrito, integrado por "aqueles que constituem e desarticulam as suas identidades mais ou menos à própria vontade, escolhendo-as no leque de ofertas extraordinariamente amplo, de abrangência planetária". Na outra extremidade, o grande grupo dos que tiveram negado o acesso à escolha da identidade e ainda têm de conviver com as identidades que thes são atribuídas pelo primeiro grupo, "identidades que estereotipam, humilham, desumanizam, estigmatizam..." (Bauman, 2005, p. 44).

É certo que o próprio Bauman relativiza essa dicotomia, afirmando estarmos, a maioria de nós, "desconfortavelmente entre esses dois polos, sem jamais ter certeza do tempo de duração de nossa liberdade de escolher o que desejamos e rejeitar o que nos desagrada" (id., ibid.). Mas a ênfase na oposição, destacando os que podem escolher sua identidade, como se estivessem em um shopping center identitário, e os que não podem sequer se livrar do estigma que lhes é impingido, faz supor a existência de seres apartados da agência, seres que não podem se mover, nem reivindicar uma ou mais identidades, quando não é bem o que se observa na teoria e no convívio social.

Para Piotr Sztompka, o passo mais importante no entendimento sociológico sobre o conceito de agência foi "quando a ideia foi estendida para baixo, a todas as pessoas em vez de apenas a uns poucos eleitos, a todos os papéis sociais e não apenas às funções de poder". Mesmo que o poder de decisão de um indivíduo na mudança social seja ínfimo, tal mudança deve ser entendida como resultado combinado daquilo que fazem todos os indivíduos (Sztompka, 2005, p. 329). É o que incomoda em algumas imagens de Bauman, sobre seres amontoados sabe-se lá em que limbo, incapazes de qualquer reação.

No que se refere à mobilidade especificamente, é bastante evidente que os deslocamentos voluntários sempre estiveram ligados a situações de privação e carência, quer pensemos em migrações regionais, como a dos retirantes brasileiros, quer tratemos dos grandes fluxos de refugiados ou da imigração ilegal que, por meio das mais diversas estratégias, toma de assalto as fronteiras de destinos cobiçados, como a Europa e os Estados Unidos. Diferentes motivações, diferentes condições, diferentes propósitos, mas em comum as situações de privação que fazem do deslocamento a "menos pior" das opções. 


\section{Desenraizamento e desterritorialização}

A análise antropológica da imigração brasileira em Portugal costuma dividi-la em duas fases ou vagas: uma primeira mais rica, mais qualificada e bem posicionada na hierarquia do mercado de trabalho, e uma segunda, a partir dos anos 1990, mais pobre, de baixa qualificação profissional e com menores perspectivas de integração (Machado, 2006a, p. 8). Evidente que, nas obras analisadas, estamos próximos da representação dessa segunda vaga, que se realiza deslocada do eixo da legalidade e da especialização. Essa migração costuma ter como situação de origem um contexto já problemático, de poucas possibilidades de ascensão social.

Em Terra estrangeira, quem melhor representa essa condição não é Paco, mas o casal de brasileiros Miguel e Alex, ele um músico medíocre que vive do mesmo esquema de contrabando que arregimenta Paco, ela garçonete em uma cantina. Miguel tem como projeto viver de música; Alex não parece ter qualquer projeto definido, fora o medo de ficar sozinha em lugar que não escolheu para viver. Paco, que vê seu mundo doméstico ruir-se com a repentina morte da mãe, é movido ainda pelo impacto da situação traumática e pela culpa de não ter dado a devida atenção ao projeto materno de rever a terra natal, San Sebastian. Não há, da parte de Paco, projeto de estabelecer-se em Portugal. Trata-se, apenas, de uma rota de passagem.

Em outros termos, pode-se dizer que em Terra estrangeira não há um projeto de reterritorialização, em que caiba ao migrante reconstruir sua casa ao mesmo tempo em que reconstitui a si mesmo (Marandola Jr.; Dal Gallo, 2009, p. 5). Há, sim, um processo de desenraizamento e desterritorialização, cujo motivo principal é de natureza econômica, como sustentam Machado e Santos (2000), mas não só. A própria noção de enraizamento, devida a Simone Weil, é bem mais rica em nuances na sua formulação original:

O enraizamento é talvez a necessidade mais importante e mais desconhecida da alma humana. É uma das mais difíceis de definir. O ser humano tem uma raiz por sua participação real, ativa e natural na existência de uma coletividade que conserva vivos certos tesouros do passado e certos pressentimentos do futuro. Participação natural, isto é, que vem automaticamente do lugar, do nascimento, da profissão, do ambiente. Cada ser humano precisa ter múltiplas raízes. Precisa receber quase que a totalidade de sua vida moral, intelectual, espiritual, por intermédio dos meios de que faz parte naturalmente. (Weil, 1996, p. 411) 
O desenraizamento, por sua vez, ocorre quando essas raízes são rompidas, seja pela força bruta das conquistas militares e conflitos civis, seja pela violência simbólica praticada em nome do poder econômico. Em Terra estrangeira, o desenraizamento de Paco é simbolizado pela morte da mãe e pela decorrente falência econômica vindo a abortar seus projetos pessoais. No entanto, mais uma vez, é Alex quem melhor representa a situação de sujeito desenraizado. Não se sabe nada sobre sua origem, a ruptura com o passado é radical, restam apenas o vazio e a incerteza do presente, manifestados em falas como "Quanto mais o tempo passa, mais eu me sinto estrangeira", "Eu não sou ninguém. (Para Paco) Você então, menos ainda", ou "Eu queria tanto voltar para casa", muito embora não saiba dizer qual seria essa casa.

Em Estive em Lisboa, de Luiz Ruffato, o tratamento metonímico possibilita uma carga maior de realismo à representação. A narrativa em primeira pessoa reivindica ao relato de Serginho o caráter de testemunho, o "estive em Lisboa" a que alude o título. Curioso, porém, é que, quando o relato se inicia (o tempo do narrador), Serginho permanece em Lisboa e parece não vislumbrar possibilidade de retorno em breve. No argumento inicial, porém, há um "escritor" que assina "L. R." e que teria editado "minimamente" o relato de Serginho, colhido em quatro sessões de gravação. A este autor, portanto, deve ser atribuída a lembrança do título, que alude tanto à comunidade brasileira em Portugal, representada pelo depoenteprotagonista, quanto a seus eventuais leitores ${ }^{3}$.

O processo de desenraizamento e desterritorialização é representado de maneira mais explícita do que em Terra estrangeira. O casamento frustrado, a paternidade complexa, o desemprego, a vida que, já na casa dos trinta, caminha para a acomodação, a morte da mãe e até mesmo o orgulho ferido pelo deboche dos amigos com seu projeto de migração - tudo contribui para a ruptura dos laços com a terra de origem. Na estrutura do livro, esse desenraizamento do protagonista é ainda simbolizado pelo abandono do cigarro. Mais uma vez, de forma metonímica, o hábito de fumar remete à identidade de Serginho, o rapagão motociclista, beberrão e namorador de cidade interiorana mineira. Identidade precarizada já antes de sua partida para Portugal, desde que deixou de fumar, conforme sua autoanálise.

A desterritorialização em si é representada pela saída do lugar-natal, a vida interiorana onde está edificada a identidade de Serginho. No en-

\footnotetext{
${ }^{3}$ O projeto editorial inclui uma "versão" da obra para o mercado português, rebatizada de Estive em Lisboa e lembrei-me de ti (Bertrand, 2010). A questão pronominal antecipa o trabalho linguístico projetado por Rufatto para representar o "antes” e o “depois” do protagonista.
} 
redo da obra, essa saída é antecedida por longos preparativos a fim de juntar os recursos para a viagem e de planejar a volta, já que o projeto do protagonista é tão claro quanto ingênuo: em um ou dois anos voltar com os "bolsos estufados", resgatar o filho sob a guarda da família da esposa, comprar algumas casas em Cataguases e viver do aluguel desses imóveis. $\mathrm{Na}$ decisão sobre o destino da viagem, tem peso decisivo a influência de seu Oliveira, português radicado na cidade, que já havia feito o trajeto várias vezes. O relato de sucesso sobre outros migrantes que optaram pelo mesmo destino irá alimentar o projeto de Serginho, como é comum nos relatos verídicos sobre o tema (Oliveira, 2006, p. 134).

\section{Estereótipo e reterritorialização}

"Estar 'longe' significa estar com problemas", sintetiza Bauman. E problemas é que não faltam para os personagens de Terra estrangeira. São todos desterrados, estrangeiros até mesmo em sua terra natal: brasileiros, angolanos e portugueses "confrontam suas (contra)narrativas identitárias, disputam espaço e reconhecem a fragilidade das fronteiras culturais no contexto contemporâneo, marcado pela diáspora" (Freire, 2009, p. 91). Uma das características principais dessas contranarrativas identitárias são os estereótipos, utilizados, uns contra os outros, na disputa pelo espaço discursivo.

Na batalha dos estereótipos, a secura pessimista dos portugueses é representada pela fala do livreiro Pedro, caracterizando um espaço existencialmente inóspito: "Isto aqui não é sítio para encontrar ninguém. É terra de gente que partiu para o mar. É o lugar ideal para perder alguém ou para perder-se de si próprio". Há também o português explorador, seu Olívio, que emprega Alex, mas guarda em relação aos brasileiros uma imagem nada positiva: "Brasileiros é tudo a mesma coisa. No princípio eles ficam mais baratos, mas depois... essa gente não nasceu para trabalhar".

O grupo de angolanos que ocupa um apartamento no andar superior ao hotel onde Paco se hospeda em Lisboa é acusado, sem fundamento, de furto e de viverem em situação de clandestinidade. Vistos com desconfiança premeditada por portugueses e brasileiros, são segregados do convívio com outros grupos, como bem exemplifica a fala de um deles, Loli, abordando também um clichê caro aos brasileiros: " - Ô, madjé, tu estás com medo de mim ou o quê? Isto não é São Paulo, Rio de Janeiro, meu. Eu não vou te fazer nada".

A forma como os grupos reagem a um estereótipo é retribuindo com outros estereótipos, uma forma de "não-conhecimento utilizada também 
como defesa" (Machado, 2006, p. 240). Os brasileiros são vistos pelos demais como preguiçosos, incompetentes, desonestos. A própria autoimagem, destacada por Alex, remete a um lugar-comum da visão nacional-derrotista: “Cruzar esse mar há 500 anos atrás... É que eles achavam que o paraíso estava ali, ó. Coitados dos portugueses... acabaram descobrindo o Brasil".

Também em Estive em Lisboa os estereótipos marcam presença, em formatos similares aos de Terra estrangeira, como ocorre com a portuguesa dona Palmira, funcionária do hotel em que Serginho hospeda-se. Ao ser alertada por este sobre o perigo de não haver ninguém na recepção do hotel, responde, raivosa: "Isso aqui não é o Brasil não, ó estúpido" (p. 43). O mesmo acontece quando os frequentadores lusos da taberna "Ao Recanto dos Caçadores" desatam a rir após Serginho, ao ser indagado sobre sua origem, declarar ser de Cataguases, Minas Gerais, "terra de gente ordeira e trabalhadora" (p. 50).

É perceptível certa ambivalência na estereotipização, tal como descrita por Homi Q. Bhabha (1998). Na visão do teórico, o estereótipo está na base do discurso colonial, atualizado pelas recentes correntes migratórias envolvendo ex-colonizadores e ex-colonizados. Como ponto primário no discurso colonial, tanto para o colonizador quanto para o colonizado, o estereótipo "é cena de uma fantasia e defesa semelhantes - o desejo de uma originalidade que é de novo ameaçada pelas diferenças de raça, cor e cultura" (Bhabha, 1998, p. 110). Na oposição entre portugueses e os grupos invasores, característica de Terra estrangeira e Estive em Lisboa, o estereótipo formulado contra um grupo acaba por definir também o grupo formulador, em sua postura autoritária que recusa o conhecimento do outro.

Em Terra estrangeira, a possibilidade de territorialização para esses grupos invasores está descartada. Para os angolanos, a perspectiva é de isolamento e guetização. Para os protagonistas brasileiros, a fuga do desfecho sugere uma viagem mais abstrata, a busca de um "eu" que supere as nacionalidades. É nesse aspecto que o filme incorre em certa fetichização do exílio (Said, 2003, p. 57), em que personagens sem maiores estigmas que a origem periférica rompem a fronteira entre Portugal e Espanha, rumo a um destino nominado, mas não definido.

Já em Estive em Lisboa, há sinais de uma reterritorialização de Serginho, embora seja difícil falar em reenraizamento. Sua adaptação à função de garçom parece apontar para um quadro de estabilidade, no qual seria possível cumprir ao menos em parte o projeto original. Sua linguagem, representada no relato, passa a incorporar vocabulário especificamente lusitano. A situação de imigrante ilegal, porém, limita as ações do protagonista, e seu envolvimento com a prostituta Sheila, brasileira como ele, 
o levará a desfazer-se de seu passaporte, o que inscreve Serginho definitivamente na clandestinidade ${ }^{4}$. No trabalho, ele é dispensado e substituído por um ucraniano, sob a alegação de que os ucranianos têm mais formação, maior domínio de línguas e alimentam projetos de "erigir uma vida nova", enquanto os brasileiros só pensam em voltar ${ }^{5}$. Acaba indo morar "de favor" e encontrando ocupação como ajudante de pedreiro, o que, para quem planejava viver de aluguel em sua terra natal, não é das situações mais confortadoras.

Ao final da obra, o projeto de Serginho é confrontado com a visão realista de outro brasileiro, Rodolfo:

"Nós estamos lascados, Serginho", aqui em Portugal não somos nada, "Nem nome temos", somos os brasileiros, "E o que a gente é no Brasil?", nada também, somos os outros.

Quanto aos projetos de retorno:

"É ilusão, Serginho", pura ilusão imaginar que uma-hora a gente volta pra nossa terra, "Volta nada".

Quanto aos projetos de economia:

"Nessa brincadeira", cinco anos escorreram já, “E sabe quanto consegui acumular? Nada... Porra nenhuma".

Para o protagonista, só mesmo voltando a fumar...

\section{Considerações finais}

O cinema e a literatura brasileiros, a partir das obras aqui discutidas, não se abstiveram da discussão sobre mobilidade e identidade, tão comum a nossos tempos. Tanto Terra estrangeira quanto Estive em Lisboa tratam da inserção da classe média baixa brasileira na grande diáspora global, muito embora a temática da película ainda esteja bastante próxima dos princípios e valores de uma elite intelectual. Terra estrangeira atualiza e reinterpreta o achado de Paulo Emílio, de que "a penosa construção de nós mesmos se desenvolve na dialética rarefeita entre o não ser e o ser

\footnotetext{
${ }^{4}$ Em Terra estrangeira, Alex também se desfaz de seu passaporte, em troca de dinheiro, o que reforça o simbolismo da situação.

${ }^{5}$ É curioso observar que os ucranianos em específico e os europeus do Leste em geral são de fato uma das maiores comunidades de estrangeiros em Portugal (Padilla, 2006, p. 22; Peixoto e Figueiredo, 2006, p. 45). Outros detalhes da obra de Rufatto beiram a observação antropológica, inclusive o desfecho, quando Serginho se emprega na construção civil, como ajudante de pedreiro. Os setores de construção e de serviços de bares e restaurantes estão dentre os que mais empregam brasileiros em Portugal (Padilla, 2006, p. 22).
} 
outro". Nessa dialética rarefeita, parece ainda haver espaço para alguma utopia, a utopia de um destino qualquer, como San Sebastian.

Para Janaína Cordeiro Freire (2009, p. 93), a utopia de Terra estrangeira consiste na indagação: "Qual o lugar das sociedades periféricas na contemporaneidade"? O fato é que as mudanças são tão rápidas, em menos de duas décadas passamos do pessimismo da Era Collor, a que o filme alude diretamente, para o otimismo econômico dos últimos anos, que vem alterando inclusive a inserção do Brasil no cenário político e econômico mundial. Em 2001, nos Estados Unidos, o ataque terrorista contra as torres gêmeas do World Trade Center, em Nova Iorque, gerou novas configurações e preocupações para o deslocamento transnacional. O estrangeiro hoje talvez pareça mais perigoso que há vinte anos, como bem exemplifica o caso do brasileiro Jean Charles de Menezes, morto em 2005, supostamente confundido com um terrorista árabe pela polícia londrina ${ }^{6}$.

O caso de Jean Charles também exemplifica que, se houve alguma mudança na inserção do país no contexto econômico internacional, a inserção social de brasileiros em terra estrangeira permanece crítica. Luiz Rufatto, em Estive em Lisboa e lembrei de você, realiza um instantâneo do atual fluxo migratório de brasileiros para Portugal, sinalizando que a mobilidade global chegou à classe média baixa, mas de forma problemática. Deslocar-se para um destino desejado, em busca de um objetivo definido, é algo hoje acessível mesmo a quem dispõe de poucos recursos. Alcançar o objetivo traçado e retornar à terra natal já é algo bem mais complicado. Essa mobilidade precária, que viabiliza, a princípio, só a passagem de ida, não guarda relação direta com mobilidade social. Ao não possibilitar o equilíbrio material e emocional almejado pelo migrante, também nega seu enraizamento na nova comunidade, resultando em isolamento, guetização e em identidade também precária.

\section{Referências bibliográficas}

BAUMAN, Zygmunt (1999). Globalização: as consequências humanas. Trad. Marcus Penchel. Rio de Janeiro: Jorge Zahar.

(2005). Identidade: entrevista a Benedetto Vecchi. Trad. Carlos Alberto Medeiros. Rio de Janeiro: Jorge Zahar.

BHABHA, Homi Q. (1998). “A outra questão: o estereótipo, a discriminação e o discurso do colonialismo." In: __ O local da cultura. Trad. Myriam Ávi-

\footnotetext{
${ }^{6}$ A história de Jean Charles serviu de argumento para filme homônimo, de 2008, dirigido por Henrique Goldman.
} 
la, Eliana Lourenço de Lima Reis e Glaucia Renate Gonçalves. Belo Horizonte: UFMG.

FREIRE, Janaína Cordeiro (2009). Identidade e exílio em terra estrangeira. São Paulo: Anablume.

HALL, Stuart (2000). “Quem precisa de identidade?" In: SILVA, Tomaz Tadeu da (Org.). Identidade e diferença: a perspectiva dos estudos culturais. Trad. Tomaz Tadeu da Silva. Petrópolis: Vozes.

(2006). “A identidade cultural na pós-modernidade". Trad. Tomaz Tadeu da Silva e Guacira Lopes Louro. 11. ed. Rio de Janeiro: DP\&A.

MACHADO, Igor José de Renó (2006a). “Introdução”. In: ___ • (Org.). Um mar de identidades: a imigração brasileira em Portugal. São Carlos: EdUFSCar. (2006b). "Estereótipos e encarceramento simbólico no cotidiano de imigrantes brasileiros no Porto". In: (Org.). Um mar de identidades: a imigração brasileira em Portugal. São Carlos: EdUFSCar. e SANTOS, Gustavo Adolfo Pedrosa Daltro (2000). “As fronteiras de Terra estrangeira". Comciencia Revista Eletrônica de Jornalismo Científico. Campinas. v. 17.

MARANDOLA JR., Eduardo; DAL GALLO, Priscila Marchiori (2009). “Ser migrante: implicações territoriais e existenciais da migração". In: VI Encontro Nacional sobre migrações. Disponível em: <http://www.abep.org.br>. Acesso em: 22 jul. 2011.

OLIVEIRA, Sérgio P. (2006). "Sem lenço, sem documento: brasileiros nãodocumentados em Portugal. In: MACHADO, Igor José de Renó. (Org.). Um mar de identidades: a imigração brasileira em Portugal. São Carlos: EdUFSCar. PADILLA, Beatriz (2006). "Integração dos 'imigrantes brasileiros recém-chegados' na sociedade portuguesa: problemas e possibilidades". In: MACHADO, Igor José de Renó. (Org.). Um mar de identidades: a imigração brasileira em Portugal. São Carlos: EdUFSCar.

PEIXOTO, João; FIGUEIREDO, Alexandra (2006). “Imigrantes brasileiros e mercado de trabalho em Portugal". In: MACHADO, Igor José de Renó. (Org.). Um mar de identidades: a imigração brasileira em Portugal. São Carlos: EdUFSCar.

RUFATTO, Luiz (2009). Estive em Lisboa e lembrei de você. São Paulo: Companhia das Letras.

SAID, Edward W. (2003). Reflexões sobre o exílio e outros ensaios. Trad. Pedro Maia Soares. São Paulo: Companhia das Letras.

SALLES GOMES, Paulo Emílio (1973). "Cinema: trajetória no subdesenvolvimento". In: Argumento: revista mensal de cultura. Rio de Janeiro: Paz e Terra. Ano 1. v. 1.

SZTOMPKA, Piotr (2005). A sociologia da mudança social. Trad. Pedro Jorgensen Jr. 2. ed. Rio de Janeiro: Civilização Brasileira.

THOMAS, Daniela; BERNSTEIN, Marcos; SALLES, Walter (1996). Terra estrangeira: roteiro. Rio de Janeiro: Rocco. 
Marco Antonio Rodrigues

WEIL, Simone (1996). A condição operária e outros estudos sobre a opressão. Org. Ecléa Bosi. Trad. Therezinha Gomes Garcia Langlada. São Paulo: Paz e Terra.

Recebido em agosto de 2011.

Aprovado em outubro de 2011.

\section{resumolabastract}

\section{Mobilidade precária em Terra estrangeira e em Estive em Lisboa e lembrei de você}

Marco Antonio Rodrigues

O artigo investiga a representação da migração da classe média baixa brasileira para Portugual no filme Terra estrangeira (1995), de Walter Salles, e na novela Estive em Lisboa e lembrei de você (2009) , de Luiz Rufatto. São abordados temas como mobilidade, identidade, desterritorialização e enraizamento. Da leitura das obras, conclui-se que elas exemplificam que a mobilidade não é privilégio exclusivo das elites, e que quando ela se realiza em condições precárias, resulta em desenraizamento e em identidade também precária.

Palavras-chave: mobilidade, identidade, desterritorialização, enraizamento, Walter Salles, Luiz Rufatto

\section{Precarious mobility in Terra Estrangeira and Estive em Lisboa e lembrei de você}

Marco Antonio Rodrigues

The article investigates the representation of the migration of lower middle-class Brazilians to Portugual in the movie Terra estrangeira (1995), by Walter Salles, and the novel Estive em Lisboa e lembrei de você (2009), by Luiz Rufatto, from topics such as mobility, identity, deterritorialization and rooting. With the reading of the works, we conclude that they exemplify that mobility is not the exclusive privilege of the elite, and when this mobility takes place in poor conditions, resulting in uprooting and identity precarious.

Key words: mobility, identity, deterritorialization, rooting, Walter Salles, Luiz Rufatto. 